\title{
REVIEW
}

\section{Cariprazine in Bipolar Disorder: Clinical Efficacy, Tolerability, and Place in Therapy}

\author{
Leslie Citrome
}

To view enhanced content go to www.advancesintherapy.com

Received: December 13, 2012 / Published online: January 28, 2013

(C) Springer Healthcare 2013

\section{ABSTRACT}

Cariprazine is a dopamine D3-preferring D3/D2 receptor partial agonist in late-stage clinical development for the treatment of bipolar disorder (manic/mixed and depressive episodes), as well as for schizophrenia, and as an adjunctive agent for the treatment of major depressive disorder. Three phase 2 or 3, 3-week, randomized controlled trials in bipolar mania or mixed episodes have been completed and reported as poster presentations or in press releases by the manufacturer. Superiority over placebo on the Young Mania Rating Scale total score was evidenced for daily doses of cariprazine 3-12 mg/day. In short-term randomized controlled trials, cariprazine does not

L. Citrome $(\bowtie)$

Clinical Professor of Psychiatry \& Behavioral Sciences, New York Medical College, Valhalla, New York, USA

11 Medical Park Drive, Suite 106, Pomona,

NY 10970, USA

e-mail: citrome@cnsconsultant.com

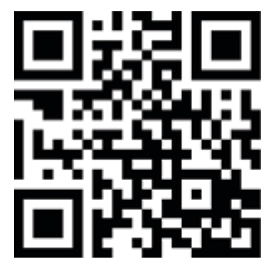

Enhanced content for Advances in Therapy articles is available on the journal web site: www.advancesintherapy.com appear to adversely impact metabolic variables, prolactin, or the electrocardiogram (ECG) QT interval. The most commonly encountered adverse events in the mania trials were extrapyramidal disorder, akathisia, insomnia, vomiting, restlessness, sedation, vision blurred, and pain in extremity in the phase 2 trial where this was presented in a poster, and akathisia, extrapyramidal disorder, tremor, dyspepsia, vomiting, dizziness, diarrhea, somnolence, restlessness, and pyrexia for the phase 3 trial where this was presented in a poster. With the exception of akathisia and extrapyramidal disorder, the differences in incidence versus placebo for these events were generally small. If approved by regulatory authorities, cariprazine would join aripiprazole as the second dopamine receptor partial agonist antipsychotic available for clinical use in persons with bipolar mania or mixed episodes. Cariprazine differs from aripiprazole in terms of dopamine D3 receptor selectivity. Further studies would be helpful to discern the distinguishing features of cariprazine from other antimanic agents.

Keywords: Antipsychotic; Bipolar disorder; Cariprazine; Depression; Dosing; Efficacy; Mania; Manic/mixed; Tolerability 


\section{INTRODUCTION}

Although there are several agents that have received regulatory approval for the treatment of bipolar disorder, it is often difficult to select the treatment(s) that will result in sufficient reduction in symptoms together with reasonable tolerability and safety. Moreover, although most available treatments are approved for the treatment of acute mania, fewer are approved for both manic and mixed episodes, fewer still for maintenance treatment, and only two for the treatment of acute bipolar depression [1, 2]. The agents themselves vary greatly in terms of ease of use and tolerability $[1,2]$.

Cariprazine is a new second-generation antipsychotic, in the late-stage of clinical development for the treatment of bipolar disorder (manic/mixed and depressive episodes), as well as for schizophrenia and as an adjunctive agent for the treatment of major depressive disorder. The intent of this review is to describe the efficacy, tolerability, and potential place in therapy of cariprazine for the treatment of bipolar disorder. A PubMed search was conducted on October 312012 using the search terms "cariprazine," "RGH-188," and "RGH 188" without any date or language restrictions. The resulting 15 publications and their reference lists were then specifically examined for primary sources of information with emphasis on the use of cariprazine in persons with bipolar disorder. A query of the ClinicalTrials.gov website on October 312012 yielded 18 separate records and provided additional information regarding registered trials of cariprazine. The abstract books for the annual scientific meetings of the American Psychiatric Association (2008-2012) [3-7], Institute on Psychiatric Services of the American Psychiatric Association (2008-2012) [8-12], New Clinical Drug Evaluation Unit (2008-2012) [13-17], and American College of Neuropsychopharmacology (2008-2011) [18-21], were also examined and yielded additional relevant data that have not yet been published as full reports in peer-refereed journals. Whenever possible, reproductions of the poster presentations were obtained in digital PDF format from the authors. Press releases from the manufacturer were also reviewed for preliminary clinical trial results that have not yet been presented at scientific meetings. A similar search strategy has been used by the author in other reviews of cariprazine, including a companion review regarding cariprazine for the treatment of schizophrenia [22], and a systematic review with emphasis on the chemistry, pharmacodynamics, and pharmacokinetics of cariprazine [23].

\section{PHARMACODYNAMICS AND PHARMACOKINETICS}

The pharmacodynamics and pharmacokinetics of cariprazine are reviewed in more detail elsewhere $[22,23]$. Cariprazine is a dopamine D3-preferring D3/D2 receptor partial agonist [24]. The in vitro binding profile of cariprazine is summarized in Table 1.

Table 1 In vitro binding affinities for cariprazine in human receptors [24]

\begin{tabular}{lll}
\hline Receptor & Ki (nM) & Comments \\
\hline Dopamine D3 & 0.085 & Partial agonist \\
Dopamine D2L & 0.49 & Partial agonist \\
Dopamine D2S & 0.69 & Partial agonist \\
Serotonin 5-HT2B & 0.58 & Antagonist \\
Serotonin 5-HT1A & 3 & Partial agonist \\
Serotonin 5-HT2A & 19 & Antagonist \\
Histamine H1 & 23 & Antagonist \\
Serotonin 5-HT7 & 111 & Antagonist \\
Serotonin 5-HT2C & 134 & Antagonist \\
\hline
\end{tabular}

$K i$ binding affinity

Lower values denotes higher affinity

Low affinity was observed for all tested adrenergic receptors 
Although the pharmacokinetics of cariprazine in subjects with bipolar disorder is not known, the pharmacokinetics of cariprazine was tested in small short-term studies in both healthy volunteers and in subjects with schizophrenia, with similar results [25]. Maximum concentration was observed in 3-4 h under fasting conditions, with food causing a slight delay but no significant effect on the extent of absorption. The mean half-life for cariprazine was 2-5 days over a dose range of $1.5-12.5 \mathrm{mg}$ in the subjects with schizophrenia. Cariprazine is metabolized by cytochrome P450 3A4 (CYP3A4) and, to a lesser extent, by cytochrome P450 2D6 (CYP2D6) [26]. There are two active metabolites of note, desmethyl-cariprazine and didesmethylcariprazine. Didesmethyl-cariprazine's half-life is substantially longer than that for cariprazine and systemic exposure to didesmethyl-cariprazine can be several times higher than that for cariprazine.

\section{SHORT-TERM CLINICAL TRIALS}

\section{Overview}

Table 2 [27-31] provides an overview of the double-blind randomized efficacy trials of cariprazine for bipolar disorder in adults, as conducted by the manufacturer. Results from one phase 2 (RGH-MD-31 [27]) and two phase 3 (RGH-MD-32 [28] and RGH-MD-33 [29]) shortterm, randomized controlled trials of cariprazine in subjects with bipolar mania/mixed episodes have been reported in posters at scientific meetings $[27,28]$ and in a press release from the manufacturer [29]. Results from a study in bipolar depression have been reported in a press release [30], and another study in bipolar depression is in progress [31].

In the studies for bipolar mania/mixed episodes, subjects could receive up to 3 weeks of randomized treatment. The primary efficacy

Table 2 Summary of double-blind randomized efficacy trials of cariprazine for bipolar disorder in adults, as conducted by the manufacturer

\begin{tabular}{|c|c|c|c|c|c|c|c|}
\hline Study & Phase & $\begin{array}{l}\text { Length } \\
\text { (weeks) }\end{array}$ & $N$ & $\begin{array}{l}\text { Cariprazine daily dose/ } \\
\text { dose ranges }(N)\end{array}$ & $\begin{array}{l}\text { Active } \\
\text { control }\end{array}$ & $\begin{array}{l}\text { Placebo, } \\
N\end{array}$ & Comments \\
\hline RGH-MD-31 [27] & 2 & 3 & 238 & $3.0-12.0 \mathrm{mg}(118)$ & None & 120 & $\begin{array}{l}\text { Acute mania. Unpublished. } \\
\text { Presented as a poster. }\end{array}$ \\
\hline RGH-MD-32 [28] & 3 & 3 & 312 & $3.0-12.0 \mathrm{mg}(158)$ & None & 154 & $\begin{array}{l}\text { Acute mania. Unpublished. } \\
\text { Presented as a poster. }\end{array}$ \\
\hline RGH-MD-33 [29] & 3 & 3 & 497 & $\begin{array}{l}3.0-6.0 \mathrm{mg}(167) \\
6.0-12.0 \mathrm{mg}(169)\end{array}$ & None & 161 & $\begin{array}{l}\text { Acute mania. Unpublished. } \\
\text { Limited information is } \\
\text { available in a press release. }\end{array}$ \\
\hline RGH-MD-52 [30] & 2 & 8 & 233 & $\begin{array}{l}0.25-0.75 \mathrm{mg}(\mathrm{ND}) \\
1.5-3.0 \mathrm{mg}(\mathrm{ND})\end{array}$ & None & ND & $\begin{array}{l}\text { Bipolar depression. } \\
\text { Unpublished. Limited } \\
\text { information is available in a } \\
\text { press release. }\end{array}$ \\
\hline RGH-MD-56 [31] & 2 & 8 & 600 & $\begin{array}{l}0.75 \mathrm{mg}(\mathrm{NA}), \\
1.5 \mathrm{mg} \text { (NA), } \\
3.0 \mathrm{mg} \text { (NA) }\end{array}$ & None & NA & $\begin{array}{l}\text { Ongoing study in bipolar } \\
\text { depression. }\end{array}$ \\
\hline
\end{tabular}

$N A$ not applicable, $N D$ not disclosed 


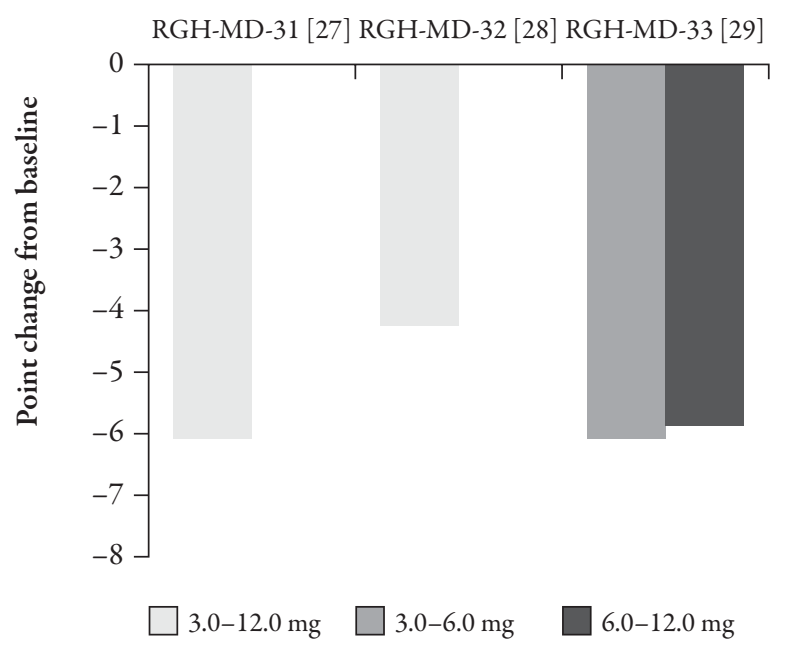

Fig. 1 Cariprazine efficacy outcomes: Young Mania Rating Scale (YMRS) total score difference from placebo, by study and daily dose, for three 3-week randomized controlled trials. All cariprazine arms were statistically significantly superior to placebo. In RGH-MD-31 [27], baseline YMRS total score was 30.2 for placebo and 30.6 for cariprazine; last observation carried forward (LOCF) change was -7.2 for placebo and -13.3 for cariprazine. In RGH-MD-32 [28], baseline YMRS total score was 32.1 for placebo and 32.3 for cariprazine; mixed-effects model of repeated measures (MMRM) change was displayed graphically in the poster and was approximately -15 for placebo and approximately -19 for cariprazine at day 21 , and the reported least squares mean difference (LSMD) was reported as -4 .3. Limited information has been reported regarding RGH-MD-33 [29]; the press release reports that the LSMD obtained by MMRM at day 21 was -6.1 for cariprazine $3-6 \mathrm{mg} /$ day and -5.9 points for cariprazine 6-12 mg/day, relative to patients receiving placebo measure was the Young Mania Rating Scale (YMRS) total score; the primary outcome was change from baseline on the YMRS total score at the 3-week endpoint. Figure 1 [27-29] provides an overview of the YMRS total score difference from placebo at endpoint for the three studies. Table 3 [27, 28] provides an overview of the outcomes of response and remission for the two studies where this was reported. All cariprazine treatment arms were statistically superior to placebo on the primary outcome. There were no active controls.

\section{RGH-MD-31}

This flexible-dose study was conducted internationally, with approximately $60 \%$ of the subjects enrolled at US sites [27]. Inclusion criteria included a diagnosis of bipolar I disorder, manic or mixed type, with or without psychotic features, YMRS score of at least 20, with a score of $\geq 4$ on at least two of four of the following YMRS items: irritability, speech, content, disruptive/aggressive behavior. Subjects were 18-65 years of age. Excluded were persons with rapid cycling, those in their first manic episode, subjects considered a suicide risk, and subjects with a Montgomery-Asberg Depression Rating Scale (MADRS) score of $\geq 18$. After up to 4 days of

Table 3 Responder and remission rates and number needed to treat (NNT) versus placebo as reported from short-term, randomized controlled trials of cariprazine for manic/mixed episodes of bipolar disorder

\begin{tabular}{|c|c|c|c|c|c|c|}
\hline & \multicolumn{3}{|c|}{ RGH-MD-31 [27] } & \multicolumn{3}{|c|}{ RGH-MD-32 [28] } \\
\hline & $\begin{array}{l}\text { Cariprazine } \\
3-12 \mathrm{mg} / \text { day } \\
(n=118)\end{array}$ & $\begin{array}{l}\text { Placebo } \\
(n=117)\end{array}$ & NNT & $\begin{array}{l}\text { Cariprazine } \\
3-12 \mathrm{mg} / \mathrm{day} \\
(n=158)\end{array}$ & $\begin{array}{l}\text { Placebo } \\
(n=152)\end{array}$ & NNT \\
\hline Responders & $48 \%$ & $25 \%$ & 5 & $59 \%$ & $44 \%$ & 7 \\
\hline Remitters & $42 \%$ & $23 \%$ & 6 & $52 \%$ & $35 \%$ & 6 \\
\hline
\end{tabular}

Response is defined as a decrease in the Young Mania Rating Scale of at least 50\% from baseline, last observation carried forward (LOCF)

Remission is defined as a Young Mania Rating Scale total score no greater than 12 at LOCF endpoint 
washout off medications in an inpatient setting, 238 subjects were randomized (safety population included 236 subjects) to cariprazine or placebo. Subjects randomized to cariprazine received $1.5 \mathrm{mg} /$ day on day 1 , and then titrated within the range of 3-12 $\mathrm{mg} /$ day based on response and tolerability as judged by the investigator. Hospitalization was mandatory during screening and the first 2 weeks of double-blind treatment. Discharge was possible on day 14 or after if the Clinical Global Impressions Severity (CGI-S) score was no greater than 3 , the subject was otherwise not at significant risk for suicide or violent behavior, and was ready for discharge in the opinion of the investigator. Mean age of subjects ranged from 38 to 39 years across the two treatment arms; male gender ranged from $65 \%$ to $68 \%$; white race ranged from $40 \%$ to $47 \%$; and baseline YMRS total score ranged from 30 to 31. In total, $36-38 \%$ of patients discontinued the trial prematurely. Mean duration of treatment was 17 days and the overall mean daily dose was $8.8 \mathrm{mg} /$ day. Cariprazine was statistically significantly superior to placebo on the primary efficacy parameter and on the CGI-S, Clinical Global Impressions-Improvement (CGI-I), and Positive and Negative Syndrome Scale (PANSS), but not on the MADRS. Compared with placebo, cariprazine-treated subjects had significantly greater rates of YMRS response (at least 50\% reduction from baseline) and remission (total score no greater than 12 ).

In an analysis of single items from the YMRS, for each YMRS item cariprazine was statistically significantly superior to placebo. Mean changes in clinical laboratory values were small and similar between the groups except for slightly higher levels in liver enzymes for the cariprazine group. Mean changes in blood pressure and pulse were higher in the cariprazine group relative to placebo. The incidence of orthostatic hypotension or ECG changes was similar between cariprazine- and placebo-treated subjects. There was a higher incidence of extrapyramidal-related symptoms in the cariprazine group relative to placebo. Treatment emergent adverse events with an incidence at least 5\% for any of the cariprazine treatment arms and at least twice that for placebo were extrapyramidal disorder, akathisia, insomnia, vomiting, restlessness, sedation, vision blurred, and pain in extremity. Differences from placebo were generally small except for extrapyramidal disorder and akathisia where the numbers needed to harm (NNH) versus placebo were 7 and 8 , respectively (see Table 4a [27]).

\section{RGH-MD-32}

This flexible-dose study was conducted internationally [28]. Inclusion criteria included a diagnosis of bipolar I disorder, manic or mixed type, with or without psychotic features, YMRS score of $\geq 20$, with a score of $\geq 4$ on at least two of four of the following YMRS items: irritability, speech, content, disruptive/aggressive behavior. Subjects were 18-65 years of age. Excluded were persons with rapid cycling, those in their first manic episode, subjects considered a suicide risk, and subjects with a MADRS score of $\geq 18$. After up to 4-7 days of washout off medications in an inpatient setting, 312 subjects were randomized to cariprazine or placebo. Subjects randomized to cariprazine received $1.5 \mathrm{mg}$ /day on day 1 . Starting on day 2 , the dose could be increased in increments of $3 \mathrm{mg}$ to a maximum of $12 \mathrm{mg} /$ day by day 7, based on patient response and tolerability. Hospitalization was mandatory during screening and the first 2 weeks of double-blind treatment. Discharge was possible on day 14 or after if the CGI-S score was no greater than 3 , the subject was otherwise not at significant risk for suicide or violent behavior, and was ready for discharge in the opinion of the investigator. Mean age of 
subjects ranged from 36 to 37 years across the two treatment arms; male gender ranged from $62 \%$ to $66 \%$; white race $21 \%$; mean body mass index ranged from 25 to $26 \mathrm{~kg} / \mathrm{m}^{2}$; and baseline YMRS total scores were approximately 32 . In total, $31-32 \%$ of patients discontinued the trial prematurely. Mean duration of treatment was 17-18 days and the overall mean daily dose was $7.5 \mathrm{mg} /$ day. Cariprazine was statistically significantly superior to placebo on the primary efficacy parameter and on the CGI-S, CGI-I, and PANSS, but not on the MADRS.

Table 4 (a) Treatment emergent adverse events with an incidence $\geq 5 \%$ for cariprazine and at least twice that for placebo from RGH-MD-31 [27] - incidence (\%) and number needed to harm (NNH) versus placebo; (b) treatment emergent adverse events with an incidence $\geq 5 \%$ for cariprazine and at least twice that for placebo from RGH-MD-32 [28] incidence $(\%)$ and number needed to harm $(\mathrm{NNH})$ versus placebo

(a)

\begin{tabular}{llll}
\hline Adverse event & Placebo $(n=118)$ & \multicolumn{2}{l}{ Cariprazine 3-12 $\mathbf{~ m g} /$ day $(n=118)$} \\
\cline { 2 - 4 } & $\%$ & $\%$ & NNH \\
\hline Extrapyramidal disorder & 9.3 & 24.6 & 7 \\
Akathisia & 5.9 & 18.6 & 17 \\
Insomnia & 2.5 & 8.5 & 20 \\
Vomiting & 3.4 & 8.5 & 20 \\
Restlessness & 0.8 & 5.9 & 20 \\
Sedation & 0.8 & 5.9 & 20 \\
Vision blurred & 0.8 & 5.9 & 39 \\
Pain in extremity & 2.5 & 5.1 & \\
\hline
\end{tabular}

(b)

\begin{tabular}{llll}
\hline Adverse event & Placebo $(n=154)$ & \multicolumn{2}{l}{ Cariprazine 3-12 $\mathrm{mg} /$ day $(n=158)$} \\
\cline { 2 - 4 } & $\%$ & $\%$ & $\mathbf{N N H}$ \\
\hline Akathisia & 4.5 & 22.8 & 6 \\
Extrapyramidal disorder & 1.9 & 15.2 & 14 \\
Tremor & 3.9 & 11.4 & 14 \\
Dyspepsia & 3.2 & 10.8 & 17 \\
Vomiting & 3.9 & 10.1 & 24 \\
Dizziness & 3.9 & 8.2 & 18 \\
Diarrhea & 1.3 & 7.0 & 23 \\
Somnolence & 1.3 & 5.7 & 20 \\
Restlessness & 0.6 & 5.7 & 32 \\
Pyrexia & 1.9 & 5.1 & \\
\hline
\end{tabular}


Compared with placebo, cariprazine-treated subjects had significantly greater rates of YMRS response and remission. Mean changes in clinical laboratory values were generally small and similar between the two groups. Similar mean decreases in prolactin levels were observed with placebo and cariprazine treatment. Mean changes in vital signs were small and similar between treatment groups with the incidence of orthostatic hypotension being similar for placebo and cariprazine. Mean changes from baseline to end of treatment in body weight were small and similar between treatment groups (placebo, $0.30 \mathrm{~kg}$; cariprazine, $0.43 \mathrm{~kg}$ ). There were no subjects receiving cariprazine who experienced an electrocardiogram (ECG) QT interval in excess of $500 \mathrm{msec}$. Treatment emergent adverse events with an incidence at least 5\% for any of the cariprazine treatment arms and at least twice that for placebo were akathisia, extrapyramidal disorder, tremor, dyspepsia, vomiting, dizziness, diarrhea, somnolence, restless, and pyrexia. Differences from placebo were generally small except for akathisia and extrapyramidal disorder where the $\mathrm{NNH}$ versus placebo were 6 and 8 , respectively (see Table 4b [28]). A total of 15 subjects receiving cariprazine discontinued because of an adverse event, with five because of akathisia.

\section{RGH-MD-33}

This study was conducted internationally [29]. Inclusion criteria included a diagnosis of bipolar I disorder, manic or mixed type, with or without psychotic features. Subjects were 18-65 years of age. After up to 4-7 days of washout off medications in an inpatient setting, 497 subjects were randomized to cariprazine 3-6 mg/day, cariprazine 6-12 mg/day, or placebo. Hospitalization was mandatory during screening and the first 2 weeks of double-blind treatment.
In total, $23-30 \%$ of patients discontinued the trial prematurely. Statistically significant improvement was observed in both cariprazine dose groups versus placebo on the primary efficacy parameter. The most common adverse events ( $\geq 10 \%$ and twice the rate of placebo) observed in the study were akathisia (both cariprazine groups) and constipation (cariprazine 6-12 mg/day). Discontinuations due to adverse events occurred in $9 \%, 15 \%$, and $5 \%$ of subjects in the cariprazine 3-6 mg/day, 6-12 mg/day, and placebo groups, respectively.

\section{RGH-MD-52}

This exploratory study was conducted in the US [30]. According to additional information contained in the study registration on the ClinicalTrials.gov website [32], inclusion criteria included persons 18-65 years of age, diagnosis of bipolar I or II disorder without psychotic features, with a current depressive episode, a verified previous manic, hypomanic, or mixed episode, score of $\geq 20$ on the Hamilton Depression Rating Scale-17 (HAMD), and score of $\geq 2$ on Item 1 of the HAMD. Excluded were persons with a score $>12$ on the YMRS, or $\geq 8$ episodes of a mood disturbance (depression, mania, hypomania, or mixed state) within the 12 months prior to visit 1 . Following a washout period of no antipsychotic therapy for at least 1 week, a total of 233 patients were randomized to cariprazine $0.25-0.75 \mathrm{mg} /$ day, cariprazine 1.5-3.0 mg/day, or placebo. The primary endpoint was change from baseline to week 8 in the MADRS total score compared to placebo treatment. The overall difference observed between cariprazine and placebo-treated subjects was not statistically significant. Approximately $9 \%$ of patients discontinued the study early due to adverse events in the high-dose study arm compared to 3\% in the placebo arm [30]. 


\section{LONG-TERM CLINICAL TRIALS}

Long-term data for cariprazine in bipolar disorder has not been publically presented. Registered on the ClinicalTrials.gov website is study RGH-MD-36 [33], a 16-week, open-label, flexible-dose study of the safety and tolerability of cariprazine in patients with bipolar I disorder. Conducted internationally, it was completed in March 2012.

\section{RANDOMIZED CONTROLLED TRIALS IN PROGRESS}

Table 2 notes an ongoing trial, RGH-MD-56, an 8-week study of cariprazine versus placebo in bipolar depression [31]. As per the study registration on the ClinicalTrials.gov website subjects with bipolar I depression without psychotic features, 18-65 years of age, and with a verified previous manic or mixed episode, a total HAMD score of $\geq 20$, a HAMD Item 1 score of $\geq 2$, and a CGI-S of $\geq 4$ would be eligible for randomization to cariprazine $0.75,1.5$, or $3.0 \mathrm{mg} /$ day, or placebo. The study is being conducted internationally.

\section{OVERALL PLACE OF CARIPRAZINE IN THERAPY}

Cariprazine represents a new treatment option for bipolar disorder and appears ready for commercialization for the indication of bipolar manic/mixed episodes. Efficacy and tolerability for this indication was established in the dose range of 3-12 mg/day. As observed in the shortterm clinical trials, there do not appear to be clinically relevant adverse effects of cariprazine on metabolic variables, prolactin, or the ECG QT interval. Additional long-term data is desirable to further characterize any longerterm treatment-related changes in body weight, metabolic variables, and movement disorders.
A recommendation in product labeling for dose titration will likely mirror that used in the clinical trials, otherwise dosing is once daily without regard to meals. When comparing cariprazine with the commercially available "metabolically-friendly" second-generation antipsychotics that have received regulatory approval for the indication of manic/mixed episodes of bipolar disorder, cariprazine most resembles aripiprazole (see Table 5 [28, 34-36]). Number need to treat (NNT) values versus placebo for response and remission are available for two of the mania trials $[27,28]$ and can be found in Table 3. The NNT for response of 5 or 7 is similar to that observed with data for lithium (NNT 4), divalproex ER (NNT 7), carbamazepine ER (NNT 4), olanzapine (NNT 5), risperidone (NNT 4), quetiapine XR (NNT 6), ziprasidone (NNT 7), aripiprazole (NNT 5), and asenapine (NNT 8) [1]. NNH values regarding akathisia for cariprazine versus placebo are approximately the same as the NNT for response, meaning that it may be equally likely to encounter one additional responder as it would be to encounter one additional patient experiencing a spontaneously reported adverse event of akathisia with cariprazine versus placebo. Provided that the akathisia is mild and timelimited this may not be a substantial obstacle for using cariprazine but in persons sensitive to akathisia this could be problematic. $\mathrm{NNH}$ values regarding somnolence for cariprazine versus placebo are similar to that for aripiprazole and appear more favorable than that observed for ziprasidone or asenapine (Table 5) [28, 34-36].

Cariprazine is a potential alternative to aripiprazole [35, 37]. Although both cariprazine and aripiprazole are dopamine receptor partial agonists, cariprazine has a different receptor binding profile, with greater affinity for the dopamine D3 receptor as the main distinguishing feature. Whether this would be clinically relevant 
Table 5 Highlights of differences and similarities among cariprazine, ziprasidone, aripiprazole, and asenapine regarding their adverse event profiles in bipolar mania/mixed episodes in adults as reported in product labeling [34-36] and available information for cariprazine (taken from RGH-MD-32 [28])

\begin{tabular}{lllll}
\hline & Cariprazine [28] & Ziprasidone [34] & Aripiprazole [35] & Asenapine [36] \\
\hline $\begin{array}{l}\text { Spontaneously reported } \\
\text { AE with incidence } \geq 5 \% \\
\text { and twice placebo }\end{array}$ & $\begin{array}{l}\text { Akathisia, } \\
\text { extrapyramidal } \\
\text { disorder, tremor, } \\
\text { dyspepsia, vomiting, } \\
\text { dizziness, diarrhea, } \\
\text { somnolence, restless, }\end{array}$ & $\begin{array}{l}\text { Somnolence, } \\
\text { extrapyramidal } \\
\text { symptoms, dizziness, } \\
\text { akathisia, abnormal } \\
\text { vision, asthenia, } \\
\text { vomiting }\end{array}$ & $\begin{array}{l}\text { Akathisia, sedation, } \\
\text { restlessness, tremor, } \\
\text { and extrapyramidal } \\
\text { disorder }\end{array}$ & $\begin{array}{l}\text { Somnolence, dizziness, } \\
\text { extrapyramidal } \\
\text { symptoms other than } \\
\text { akathisia, and weight } \\
\text { gain }\end{array}$ \\
AE - somnolence, NNH & 23 & 6 & & \\
AE- akathisia, NNH & 6 & 20 & 20 (sedation) & 6 \\
Prolactin warning? & No & Yes & 12 & 50 \\
QT warning? & No & Yes & No & Yes \\
\hline
\end{tabular}

$A E$ adverse event, $N N H$ number needed to harm (calculated as the reciprocal of the incidence of the AE on the drug of interest minus the incidence of the $\mathrm{AE}$ for placebo, and then rounded to the next highest whole number) from data contained in product labeling (prescribing information) available from the manufacturers [34-36]

requires additional randomized controlled trials that are specifically designed and powered to contrast cariprazine with aripiprazole at optimal doses. Regarding the latter, it is unclear which doses of cariprazine would offer the best balance in terms of efficacy and tolerability. In terms of drug-induced extrapyramidal adverse events and akathisia it will be important to further characterize possible dose response and the time course that these effects follow. This may be a complex undertaking, given the long halflife of didesmethyl-cariprazine, one of the two important active metabolites of cariprazine.

Cost will likely be a consideration given the availability of generic second-generation antipsychotics, including the future emergence of generic formulations of aripiprazole. However, should cariprazine receive regulatory approval for the treatment of bipolar depression, the scarcity of available alternatives for this indication bodes well for the commercial success of cariprazine.
At present, available data are limited to shortterm trials with constrained inclusion/exclusion criteria that can limit their generalizability. Longerterm trials will be necessary to further characterize cariprazine's efficacy, tolerability, and safety profile, including effects on metabolic variables. Relapse prevention studies would also potentially inform clinicians about cariprazine's potential for the prevention of manic or depressive episodes associated with bipolar disorder. The inclusion of active comparators in studies will further clarify cariprazine's place in therapy.

An important caveat is that none of the efficacy studies discussed have been published in peer-reviewed journals, and so the data presented must be considered preliminary and subject to revision.

Logical candidates for cariprazine treatment would be adults with bipolar manic/mixed episodes for whom sedation, metabolic, or cardiovascular risk is a concern, and for whom weight gain is to be minimized or avoided. 
Patients who are sensitive to akathisia and extrapyramidal effects will need to be monitored for these adverse drug reactions.

\section{CONCLUSIONS}

If commercialized, cariprazine will be a new treatment option for bipolar disorder. Based on the short-term studies conducted by the manufacturer, efficacy and tolerability for manic/mixed episodes was established in the dose range of 3-12 mg/day. There doesn't appear to be clinically relevant adverse effects of cariprazine on metabolic variables, prolactin, or the ECG QT interval. The incidence of extrapyramidal side effects and akathisia appear higher for cariprazine-treated subjects with bipolar disorder than those with schizophrenia. Longer-term tolerability information in subjects with bipolar disorder is not yet available. Additional clinical trials are underway for the use of cariprazine in bipolar depression and major depressive disorder.

\section{ACKNOWLEDGMENTS}

No writing assistance was utilized in the production of this review. The manufacturer (Forest Laboratories, Inc.) had no substantive role in the creation of the manuscript but was offered the opportunity to comment on any possible inaccuracies prior to peer review. Dr. Citrome is the guarantor for this article, and takes responsibility for the integrity of the work as a whole.

Conflict of interest. In the past 36 months, Leslie Citrome has engaged in collaborative research with, or received consulting or speaking fees, from: Alexza, Alkermes, AstraZeneca, Avanir, Bristol-Myers Squibb, Eli Lilly, Forest, Genentech, Janssen, Lundbeck, Merck, Novartis, Noven, Otsuka, Pfizer, Shire, Sunovion, and Valeant.

\section{REFERENCES}

1. Ketter TA, Citrome L, Wang PW, Culver JL, Srivastava S. Treatments for bipolar disorder: can number needed to treat/harm help inform clinical decisions? Acta Psychiatr Scand. 2011;123:175-89.

2. Ketter TA, Wang PW. Chapter 5: Overview of pharmacotherapy for bipolar disorders. In: Ketter TA. Handbook of Diagnosis and Treatment of Bipolar Disorder. Washington, DC: American Psychiatric Publishing, Inc.; 2010:83-106.

3. American Psychiatric Association. New Research Abstracts, $161^{\text {st }}$ Annual Meeting of the American Psychiatric Association; May 3-8, 2008; Washington, DC.

4. American Psychiatric Association. New Research Abstracts, $162^{\text {nd }}$ Annual Meeting of the American Psychiatric Association; May 16-21, 2009; San Francisco, CA.

5. American Psychiatric Association. New Research Abstracts, $163^{\text {rd }}$ Annual Meeting of the American Psychiatric Association; May 22-26, 2010; New Orleans, LA.

6. American Psychiatric Association. New Research Abstracts, $164^{\text {th }}$ Annual Meeting of the American Psychiatric Association; May 14-18, 2011; Honolulu, HI.

7. American Psychiatric Association. New Research Abstracts, $165^{\text {th }}$ Annual Meeting of the American Psychiatric Association; May 5-9, 2012; Philadelphia, PA.

8. American Psychiatric Association. Syllabus and Proceedings Summary, $60^{\text {th }}$ Institute on Psychiatric Services; October 2-5, 2008; Chicago, IL.

9. American Psychiatric Association. Syllabus and Proceedings Summary, $61^{\text {st }}$ Institute on Psychiatric Services; October 8-11, 2009; New York, NY.

10. American Psychiatric Association. Syllabus and Proceedings Summary, $62^{\text {nd }}$ Institute on Psychiatric Services; October 14-17, 2010; Boston, MA.

11. American Psychiatric Association. Syllabus and Proceedings Summary, $63^{\text {rd }}$ Institute on Psychiatric Services; October 27-30, 2011; San Francisco, CA.

12. American Psychiatric Association. Syllabus and Proceedings Summary, $64^{\text {th }}$ Institute on Psychiatric Services, New York City, New York, October 4-7, 2012. 
13. National Institute of Mental Health and American Society of Clinical Psychopharmacology. Poster Abstracts. 48 ${ }^{\text {th }}$ Annual NCDEU Meeting; May 27-30, 2008; Phoenix, AZ.

14. National Institute of Mental Health and American Society of Clinical Psychopharmacology. Poster Abstracts. 49 $9^{\text {th }}$ Annual NCDEU Meeting; June 29July 2, 2009; Hollywood, FL.

15. National Institute of Mental Health and American Society of Clinical Psychopharmacology. Poster Abstracts. 50 ${ }^{\text {th }}$ Annual NCDEU Meeting; June 1417, 2010; Boca Raton, FL.

16. American Society of Clinical Psychopharmacology. Poster Abstracts. 51 ${ }^{\text {st }}$ Annual NCDEU Meeting; June 14-17, 2011; Boca Raton, FL.

17. American Society of Clinical Psychopharmacology. Poster Abstracts. 52 ${ }^{\text {nd }}$ Annual NCDEU Meeting; May 29-June 1, 2012; Phoenix, AZ.

18. American College of Neuropsychopharmacology. Program book. 47 $7^{\text {th }}$ Annual Meeting; December 7-11, 2008; Scottsdale, AZ.

19. American College of Neuropsychopharmacology. Program book. $48^{\text {th }}$ Annual Meeting; December 6-10, 2009; Hollywood, FL.

20. American College of Neuropsychopharmacology. Program book. 49 ${ }^{\text {th }}$ Annual Meeting; December 5-9, 2010; Miami Beach, FL.

21. American College of Neuropsychopharmacology. Program book. 50 th Annual Meeting; December 4-8, 2011; Waikoloa Beach, HI.

22. Citrome L. Cariprazine in schizophrenia: clinical efficacy, tolerability, and place in therapy. Adv Ther. 2013;30:114-26.

23. Citrome L. Cariprazine: chemistry, pharmacodynamics, pharmacokinetics and metabolism, clinical efficacy, safety and tolerability. Expert Opin Drug Metab Toxicol. 2013;9:193-206.

24. Kiss B, Horváth A, Némethy $Z$, et al. Cariprazine (RGH-188), a dopamine $\mathrm{D}(3)$ receptor-preferring, $\mathrm{D}(3) / \mathrm{D}(2)$ dopamine receptor antagonist-partial agonist antipsychotic candidate: in vitro and neurochemical profile. J Pharmacol Exp Ther. 2010;333:328-40.

25. Kapas M, Meszaros GP, Yu B, et al. Comparison of the pharmacokinetic behaviour of RGH-188 in schizophrenic patients and healthy volunteers. Eur Neuropsychopharmacol. 2008;18:433.
26. Kirschner $\mathrm{N}$, Gemesi LI, Vastag $\mathrm{M}$, et al. In vitro metabolism of RGH-188. Drug Metab Rev. 2008;40:128-9.

27. Knesevich MA, Papadakis K, Bose A, et al. The efficacy and tolerability of cariprazine in acute mania associated with bipolar disorder: a phase II trial. Poster presentation NR1-49, American Psychiatric Association $162^{\text {nd }}$ Annual Meeting; May 16-21, 2009; San Francisco, CA.

28. Starace A, Bose A, Wang Q, et al. Cariprazine in the treatment of acute mania in bipolar disorder: a double-blind, placebo-controlled, Phase III trial. Poster presentation NR9-42, American Psychiatric Association $165^{\text {th }}$ Annual Meeting; May 5-9, 2012; Philadelphia, PA.

29. Forest Laboratories, Inc. and Gedeon Richter Plc anounce positive phase III results with the investigational antipsychotic cariprazine in patients with acute mania associated with bipolar I disorder [press release]. Forest Laboratories, Inc.; 8 February 2012. Available at: http://news.frx.com/press-release/product-news/ forest-laboratories-inc-and-gedeon-richter-plcannounce-positive-phase-ii. Accessed November 6 2012 .

30. Forest Laboratories, Inc. and Gedeon Richter Plc announce results from a phase II study of cariprazine for the treatment of bipolar depression [press release]. Forest Laboratories, Inc.; 30 August 2010. Available at: http://news.frx.com/press-release/rd-news/ forest-laboratories-inc-and-gedeon-richterplc-announce-results-phase-ii-stu-0. Accessed November 62012.

31. Safety, tolerability, and efficacy of cariprazine for patients with bipolar depression. Forest Laboratories, Inc. ClinicalTrials.gov website. Available at: http://clinicaltrials.gov/ct2/show/NCT01396447. Accessed November 62012.

32. Safety and efficacy of RGH-188 (cariprazine) in bipolar depression. Forest Laboratories, Inc. ClinicalTrials.gov website. Available at: http://clinicaltrials.gov/ct2/show/NCT00852202. Accessed November 62012.

33. Long-term safety and tolerability of cariprazine for bipolar I disorder. Forest Laboratories, Inc. ClinicalTrials.gov website. Available at: http://clinicaltrials.gov/ct2/show/NCT01059539. Accessed November 62012. 
34. Geodon (ziprasidone) [product information]. Pfizer, NY, USA; revised October 2012. Available at: http:// labeling.pfizer.com/ShowLabeling. aspx?id=584. Accessed January 112013.

35. Abilify (aripiprazole) [product information]. Otsuka Pharmaceutical Co., Tokyo, Japan; revised February 2012. Available at: http://www.abilify. com/pdf/pi.aspx. Accessed November 122012.
36. Saphris (asenapine) [product information]. Merck \& Co., NJ, USA; revised October 2012. Available at: http://www.merck.com/product/usa/pi_circulars/s/ saphris/saphris_pi.pdf. Accessed January 112013.

37. Citrome L. A review of aripiprazole in the treatment of patients with schizophrenia or bipolar I disorder. Neuropsychiatr Dis Treat. 2006;2:427-43. 